\title{
HPr kinase/phosphatase of Bacillus subtilis: expression of the gene and effects of mutations on enzyme activity, growth and carbon catabolite repression
}

\author{
K. G. Hanson, ${ }^{1,2}$ Katrin Steinhauer, ${ }^{1}$ Jonathan Reizer, $†$ Wolfgang Hillen ${ }^{1}$ \\ and Jörg Stülke ${ }^{1}$
}

Author for correspondence: Jörg Stülke. Tel: +499131 8528818. Fax: +49 91318528082. e-mail: jstuelke@biologie.uni-erlangen.de

1 Lehrstuhl für

Mikrobiologie, Institut für Mikrobiologie, Biochemie und Genetik der FriedrichAlexander-Universität Erlangen-Nürnberg, Staudtstr. 5, D-91058 Erlangen, Germany

2 Birla Institute of Scientific Research, Statue Circle, Jaipur 302001, Rajasthan, India

\begin{abstract}
HPr kinase/phosphatase (HPrK/P) is the key protein in regulation of carbon metabolism in Bacillus subtilis and many other Gram-positive bacteria. Whether this enzyme acts as a kinase or phosphatase is determined by the nutrient status of the cell. Mutational analysis of residues in a Walker $A$ box nucleotide-binding motif revealed that it is not only important for kinase but is also involved in phosphatase activity. In addition, a signature sequence specifically conserved among HPrK/P orthologues is required for phosphatase activity and may be involved in interaction with HPr/HPr-(Ser46)-P. Carbon catabolite repression was abolished in a $B$. subtilis strain expressing a mutant form of HPrK/P deficient in kinase and phosphatase activities. The growth characteristics of this strain were similar to those of the wild-type. In contrast, B. subtilis strains expressing HPrK/P with partial kinase and no phosphatase activities showed growth impairment but exhibited catabolite repression.
\end{abstract}

Keywords: phosphorylation, glycolysis, Walker A box, mutagenesis

\section{INTRODUCTION}

Bacteria have the ability to preferentially utilize, out of a mixture of carbon sources, compounds which allow them to grow at a maximal rate. The underlying regulatory mechanisms are collectively called carbon catabolite repression (CCR). Highly sophisticated signal transduction networks collect and integrate information about the physiological state of the cell and the availability of carbon sources, and fine-tune the expression of catabolic enzymes.

CCR in Bacillus subtilis is governed by the phosphorylation state of $\mathrm{HPr}$, a phosphotransfer protein of the phosphotransferase system (PTS) for the uptake of sugars and its regulatory homologue Crh (Stülke \&

Abbreviations: $C C R$, carbon catabolite repression; $F B P$, fructose 1,6bisphosphate; HPrK/P, HPr kinase/phosphatase; PTS, phosphotransferase system.

†J.R. deceased on 31 December 1999; he was formerly at the Department of Biology, University of California at San Diego, La Jolla, CA 92093-0116, USA.
Hillen, 2000). The regulatory phosphorylations of $\mathrm{HPr}$ and Crh are catalysed by the bifunctional HPr kinase/ phosphatase (HPrK/P), the prototype of a new family of ATP-dependent protein kinases (Galinier et al., 1998; Reizer et al., 1998; Kravanja et al., 1999). This regulatory phosphorylation occurs at Ser46 of HPr and inhibits phosphorylation at His15 and, thereby, all enzymic and regulatory events depending on this form of HPr (Deutscher \& Saier, 1983; Stülke \& Hillen, 2000). HPr-Ser46-P and Crh-Ser46-P are cofactors of the pleiotropic transcriptional regulator CcpA and enhance its affinity for catabolite-responsive DNA sequences that are often found in catabolic genes and operons (Deutscher et al., 1995; Jones et al., 1997; Galinier et al., 1999).

HPrK/P senses the physiological state of the cell and responds with changes of the kinase and phosphatase activities. HPr kinase activity in B. subtilis is dependent on glycolytic intermediates such as fructose 1,6-bisphosphate (FBP) and is inhibited by inorganic phosphate. Cooperativity for ATP and FBP binding has recently been reported for HPrK/P of B. subtilis (Jault et al., 2000). In contrast, HPr phosphatase activity is stimulat- 
ed by inorganic phosphate (Galinier et al., 1998; Reizer et al., 1998; Kravanja et al., 1999). The HPr kinases of different bacteria do not respond in the same way to the same metabolites, e.g. the orthologues of Enterococcus faecalis and Streptococcus salivarius are activated by high ATP concentrations and are independent of FBP (Brochu \& Vadeboncoeur, 1999; Kravanja et al., 1999).

Genes encoding HPrK/P have been identified in several Gram-positive bacteria and in proteobacteria such as Neisseria gonorrboeae and N. meningitidis (Brochu \& Vadeboncoeur, 1999; Dossonnet et al., 2000; Himmelreich et al., 1996; Huynh et al., 2000; Reizer et al., 1998). Inactivation of the hprK gene in B. subtilis (Galinier et al., 1998; Martin-Verstraete et al., 1999; Reizer et al., 1998), Staphylococcus xylosus (Huynh et al., 2000) and Lactobacillus casei (Dossonnet et al., 2000) results in abolition of CCR.

In this work we have identified some amino acids important for phosphatase and kinase activities of $B$. subtilis $\mathrm{HprK} / \mathrm{P}$. B. subtilis strains carrying mutations affecting these amino acids show growth defects and/or impaired CCR. To our knowledge, this is the first report demonstrating the in vitro and in vivo effects of site-directed mutations introduced into $\mathrm{HPrK} / \mathrm{P}$ of B. subtilis.

\section{METHODS}

Bacterial strains and growth conditions. E. coli $\mathrm{DH} 5 \alpha$ (Sambrook et al., 1989) was used for cloning experiments and for expression of recombinant proteins. B. subtilis strains used in this study are listed in Table 1 . They were routinely grown in SP medium or in CSE minimal medium (Faires et al., 1999) supplemented with tryptophan $\left(50 \mathrm{mg} \mathrm{l}^{-1}\right)$ and chlorampheni$\mathrm{col}\left(\mathrm{Cm} ; 5 \mathrm{mg} \mathrm{l}^{-1}\right)$ as required. E. coli was grown in LB medium and transformants were selected on plates containing ampicillin $\left(100 \mathrm{mg} \mathrm{l}^{-1}\right)$. LB and SP plates were prepared by the

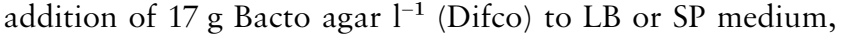
respectively.

DNA manipulation and plasmid constructions. Transformation of E. coli and plasmid DNA extraction were performed using standard procedures (Sambrook et al., 1989). Restriction enzymes, T4 DNA ligase and DNA polymerases were used as recommended by the manufacturers. DNA fragments were purified from agarose gels using the Nucleotrap Gel Extraction kit (Macherey \& Nagel). DNA sequences were determined with an ABI PRISM 310 Genetic Analyser using the protocol recommended by the manufacturer (PE Applied Biosystems).

A transcriptional fusion of the $h p r K$ promoter region with the lacZ gene was constructed using the vector pAC6 (Stülke et al., 1997) containing a chloramphenicol-resistance gene. The plasmid harbours a lacZ gene without a promoter located between two fragments of the B. subtilis amyE gene. A DNA fragment of the promoter region of $h p r K$ was amplified by PCR using chromosomal DNA of B. subtilis 168 and the primers KS1 (5'-AATGAATTCCCGTCATTGATTCCGACATAGCCG-3') and KS2 (5'-AATGGATCCTACCTGGTCTTGATAGGTCACTCATTGT-3'). The PCR product was digested with EcoRI and BamHI and cloned into pAC6 cut with the same enzymes. The resulting plasmid pGP201 was used to introduce the $h p r K-l a c Z$ fusion into the chromosome of B. subtilis 168 .

Plasmid pGP211 was constructed to disrupt the chromosomal $h p r K$ gene by a $s p c$ gene endowing $B$. subtilis with spectinomycin resistance. First, pBluescript $\mathrm{SK}^{+}$(Stratagene Cloning Systems) was digested with $S p e \mathrm{I}$ and $\mathrm{XbaI}$ and the linearized fragment religated to give pGP208. The $h p r K$ gene region was amplified from the chromosome of B. subtilis 168 using primers KS20 (5'-ATTGAATTCTGCTGATCCTCCTCCGGCGCAAGT-3') and KS21 (5'-ATTGAGCTCTCCGCAAGCTTCCAGAACGAAAGG-3'). The $2 \cdot 1 \mathrm{~kb}$ amplicon was digested with HindIII and the resulting $1.7 \mathrm{~kb}$ fragment cloned into pGP208. The resulting plasmid was pGP209. The spectinomycin-resistance gene was isolated from pGP109 (Reizer et al., 1999) using primers KS32 (5'-AAAAGCGCTATAGCTAGGGTAAGTAAATTGAGTA-3') and KS33 (5'AAAAGCGCTCTACTAATTGAGAGAAGTTTCTATAGA-3'). This PCR product was digested with Eco47III and cloned into the Eco47III site of pGP209. A plasmid that contained the $s p c$ gene inserted in the same direction as the (disrupted) $h p r K$ gene was chosen and designated pGP211.

To overexpress the wild-type $\mathrm{HPrK} / \mathrm{P}$ protein fused to a hexahistidine sequence at the $\mathrm{N}$ terminus, plasmids were constructed as follows. The DNA fragment corresponding to the $h p r K$ ORF was amplified by PCR using chromosomal DNA of $B$. subtilis 168 and the primer pair KS11 (5'AAAGTCGACATGGCAAAGGTTCGCACAAAAGACGTAATGG-3') and KS12 (5'-AAAAAGCTTGGTTCTATCGCTTCATTCATTTAACGC-3'), containing SalI and HindIII

Table 1. B. subtilis strains used in this work

\begin{tabular}{|c|c|c|}
\hline Strain & Genotype & Source or reference* \\
\hline 168 & $\operatorname{trp} C 2$ & Laboratory stock \\
\hline QB7144 & $\operatorname{trp} C 2$ amyE: $(x y n P-l a c Z$ cat $)$ & Galinier et al. (1999) \\
\hline GP201 & $\operatorname{trp} C 2$ amyE: $($ hprK-lacZ cat $)$ & pGP201 $\rightarrow 168$ \\
\hline GP202 & $\operatorname{trp} C 2$ hprK::spc & pGP211 $\rightarrow 168$ \\
\hline GP406 & $\operatorname{trp} C 2$ amyE:: (xynP-lacZ cat) hprK G148A & QB7144 + pGP406 $\rightarrow 168+$ \\
\hline GP407 & $\operatorname{trp} C 2$ amyE: : (xynP-lacZ cat) hprK G158A & $\mathrm{QB} 7144+\mathrm{pGP} 407 \rightarrow 168+$ \\
\hline GP408 & $\operatorname{trp} C 2$ amyE: : (xynP-lacZ cat) hprK G207A & QB7144+ pGP408 $\rightarrow 168+$ \\
\hline
\end{tabular}

*Arrows indicate construction by transformation.

† These strains were constructed by congression as described in Results and Discussion. 
Table 2. Mutations introduced into the $h p r K$ gene by two-step site-directed mutagenesis using the mutagenic primers

\begin{tabular}{|llll|}
\hline Mutation & Mutagenic primer & Sequence $\left(\mathbf{5}^{\prime}-\mathbf{3}^{\prime}\right)^{* *}$ & $\begin{array}{c}\text { Resulting } \\
\text { plasmid } \dagger\end{array}$ \\
\hline G148A & KS22 & ATATATGGTGTCGCAGTGCTGATCACAGGA & pGP406 \\
G153A & KS23 & GTGCTGATCACAGCAAAAAGCGGCGTC & pGP409 \\
S155T & KS26 & ATCACAGGAAAAACAGGCGTCGGAAAAAGC & pGP410 \\
S155A & MM2 & ACAGGAAAAGCCGGCGTCGGA & pGP412 \\
G158A & KS25 & AAAAGCGGCGTCGCAAAAAGCGAAACA & pGP407 \\
S160T & KS27 & GGCGTCGGAAAAACAGAAAGAGCGCTA & pGP408 \\
G207A & KS29 & GAGATCAGGGGCCTTGCAATTATCAATGTG & \\
\hline
\end{tabular}

* The relevant mutations introduced by the mutagenic primers are underlined.

† The PCR products obtained after two-step site-directed mutagenesis were cloned after cleavage with HindIII and SalI into pWH844 cleaved with the same restriction enzymes.

restriction sites respectively. After digestion of the PCR products with these restriction enzymes, the resulting fragments were cloned into the expression vector pWH844 (Schirmer et al., 1997) cut with the same enzymes. The resulting plasmid was pGP205 (for the wild-type gene). Plasmid pAG2 (Galinier et al., 1997) was used for the production of (His) ${ }_{6} \mathrm{HPr}$ from B. subtilis.

Site-directed mutagenesis of hprK. Site-directed mutagenesis of the hprK gene was carried out using a two-step PCR protocol as described earlier (Bachem et al., 1997). KS11 and KS12 served as the outer primers. After mutations were introduced using mutagenic primers the PCR products were cloned between the SalI and HindIII sites of pWH844 as described for the wild-type gene. The mutagenic primers and the resulting plasmids are listed in Table 2.

Construction of $B$. subtilis strains carrying point mutations in the $h p r K$ gene. A strain containing the $h p r K$ G148A allele was constructed by cotransformation of B. subtilis 168 with chromosomal DNA of strain QB7144 [amyE::(xynP-lacZ cat)] and plasmid pGP406. Transformants were screened on CSE plates containing $\mathrm{Cm}$, glucose and xylose. A strain lacking $\mathrm{HPr}-($ Ser46)-P was expected to express the $x y n P-l a c Z$ in the presence of glucose whereas $x y n P$ expression would be repressed in the wild-type due to the very severe repression of the $x y n P B$ operon by glucose (Lindner et al., 1994; Galinier et al., 1999). The reverse strategy was followed to isolate transformants expressing $\mathrm{HPrK} / \mathrm{P}$ devoid of phosphatase activity. Recombination of only ( $x y n P-l a c Z$ cat) genes into the chromosomal amyE locus was expected to result in formation of Cm-resistant blue colonies on plates containing $\mathrm{Cm}$ and xylose since lacZ expression would be induced by xylose. In contrast, recombination of the mutant alleles $h p r K$ G158A or hprK G207A and (xynP-lacZ cat) genes would result in white colonies, because $\mathrm{HPr}-(\mathrm{Ser} 46)-\mathrm{P}$ together with CcpA would continuously repress the $x y n P-l a c Z$ fusion. Appropriate transformants obtained from both the above procedures were isolated and after amplification of the $h p r K$ alleles from the chromosome by PCR, the presence of the required mutations was confirmed by sequencing.

Protein purification. E. coli DH5 $\alpha$ was used as host for the overexpression of recombinant proteins. Expression was induced by the addition of IPTG (final concentration $1 \mathrm{mM}$ ) to exponentially growing cultures $\left(\mathrm{OD}_{600} 0 \cdot 8\right)$. After sonication, the lysates were centrifuged at $15000 \mathrm{~g}$ for $30 \mathrm{~min}$ and the resulting supernatants were passed over a $\mathrm{Ni}^{2+}$ HiTrap chelating column (Pharmacia) followed by elution with an imidazole gradient. The Bio-Rad dye-binding assay was used to determine protein concentration. Bovine serum albumin was used as the standard.

Activity assays of HPrK/P. Activity assays were carried out with purified $\mathrm{HPrK} / \mathrm{P}$ in a total volume of $20 \mu \mathrm{l}$ containing assay buffer $(10 \mathrm{mM} \mathrm{MgCl}, 25 \mathrm{mM}$ Tris/ $\mathrm{HCl} \mathrm{pH} \mathrm{7.5,} 1 \mathrm{mM}$ dithiothreitol), purified $\mathrm{HPrK} / \mathrm{P}(350 \mathrm{nM})$ and (His) ${ }_{6} \mathrm{HPr}$ or (His) ${ }_{6} \mathrm{HPr}-\mathrm{Ser}-\mathrm{P}(4 \mu \mathrm{g}$ per reaction) of $B$. subtilis. ATP, inorganic phosphate $\left(\mathrm{P}_{\mathrm{i}}\right.$; as potassium phosphate) and FBP were added as indicated. The assays were carried out at $37^{\circ} \mathrm{C}$ for $15 \mathrm{~min}$ followed by thermal inactivation of the enzyme $\left(4 \mathrm{~min}\right.$ at $\left.95^{\circ} \mathrm{C}\right)$. The assay mixtures were analysed on $7.5 \%$ native polyacrylamide gels. (His) ${ }_{6} \mathrm{HPr}-\mathrm{Ser}-\mathrm{P}$ was prepared as follows. After incubation of (His) ${ }_{6} \mathrm{HPr}$ with $\mathrm{HPrK} / \mathrm{P}$ in assay buffer in the presence of $10 \mathrm{mM}$ ATP and $20 \mathrm{mM}$ FBP the enzyme was thermally inactivated. (His) ${ }_{6} \mathrm{HPr}-\mathrm{Ser}-\mathrm{P}$ was purified by FPLC using a Poros 20HQ anion-exchange column (Perkin Elmer PerSeptive Biosystems) with a $0-500 \mathrm{mM} \mathrm{NaCl}$ (in $10 \mathrm{mM}$ Tris/ $\mathrm{HCl} \mathrm{pH} \mathrm{7.5)} \mathrm{gradient} \mathrm{as} \mathrm{described} \mathrm{by} \mathrm{Deut-}$ scher \& Engelmann (1984).

Transformation and characterization of phenotype. B. subtilis 168 was co-transformed with plasmid DNA carrying the $h p r K$ gene with the required mutation and chromosomal DNA of strain QB7144 according to the two-step protocol described by Kunst \& Rapoport (1995). Quantitative studies of lacZ expression in B. subtilis in liquid medium were performed as follows. Cells were grown in CSE medium containing xylose $\left(1 \mathrm{~g} \mathrm{l}^{-1}\right)$ as inducer with or without glucose $\left(5 \mathrm{~g} \mathrm{l}^{-1}\right)$ and $\mathrm{Cm}\left(5 \mathrm{mg} \mathrm{l}^{-1}\right)$. The cells were harvested at $\mathrm{OD}_{600}$ $0 \cdot 6-0.8$ and lysed by treatment with lysozyme and DNase. $\beta$-Galactosidase activities were determined as previously described using ONPG as substrate (Miller, 1972). One unit is defined as the amount of enzyme which produces $1 \mathrm{nmol}$ $o$-nitrophenol $\min ^{-1}$ at $28^{\circ} \mathrm{C}$. Doubling times were estimated from a semi-logarithmic plot of $\mathrm{OD}_{600}$ vs time. Assays of $\beta$-galactosidase activities and growth rates were performed in duplicate or triplicate. Representative results are shown.

Western blot analysis. For Western blot analysis, cell extracts were separated on $12.5 \%$ SDS-polyacrylamide gels and transferred to a PVDF membrane (Fluorotrans) by electroblotting. HPrK/P was detected with the rabbit polyclonal antiserum raised against $\mathrm{HPrK} / \mathrm{P}$ of $B$. subtilis. $\mathrm{HPrK} / \mathrm{P}$ antibodies on the PVDF membrane were visualized by using the ECL Western blot analysis system (Amersham). 


\section{RESULTS AND DISCUSSION}

\section{Expression of the hprK gene in B. subtilis}

Kinase activity of $\mathrm{HPrK} / \mathrm{P}$ is triggered if bacteria are grown under conditions allowing high glycolytic activity. We addressed the question whether the intracellular level of HPrK/P is also increased under these conditions by two sets of experiments. We constructed a transcriptional fusion of the $h p r K$ promoter region to a promoterless lac $Z$ gene and inserted it into the chromosome of $B$. subtilis 168 . $\beta$-Galactosidase activity of the resulting strain, GP201, during growth in CSE minimal medium in the presence or absence of glucose was low and not affected by the presence of glucose [10-14 units $\beta$-galactosidase (mg protein $\left.)^{-1}\right]$, indicating weak constitutive transcription of $h p r K$.

Although transcription of the $h p r K$ gene was constitutive, a post-transcriptional regulation of the synthesis of $\mathrm{HPrK} / \mathrm{P}$ could not be ruled out. Therefore, we assayed the amounts of $\mathrm{HPrK} / \mathrm{P}$ in extracts of $B$. subtilis cells by Western blot analysis. B. subtilis 168 was grown in complex medium and in CSE minimal medium with or without glucose. As controls we used purified (His) ${ }_{6} \mathrm{HPrK}$ as well as cell extracts of E. coli and the $B$. subtilis hprK mutant strain GP202. As shown in Fig. 1, the antibody reacted with a single protein in extracts of $B$. subtilis 168 but no signal was observed with E. coli or the $h p r K$ mutant strain. $\mathrm{HPrK} / \mathrm{P}$ was present in cell extracts grown in complex medium and in minimal medium irrespective of the presence of glucose. These results suggest that HPr phosphorylation/dephosphorylation may not be regulated at the level of HPr kinase synthesis but rather exclusively by the enzyme's activity.

\section{Site-directed mutagenesis of HPrK/P}

The HPrK/P of B. subtilis is the prototype of a novel class of protein kinases and phosphatases (Galinier et al., 1998; Reizer et al., 1998). Among HPrK/P proteins, two highly conserved regions have been identified: an

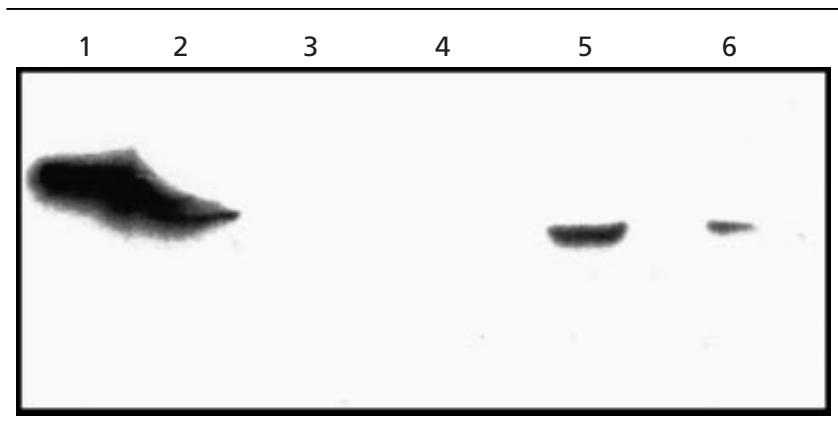

Fig. 1. Western blot analysis of HPrK/P expression in B. subtilis. Lane 1, $500 \mathrm{ng}$ (His) ${ }_{6}$-HPrK/P; lanes $2-6,60 \mu \mathrm{g}$ of cell extracts were loaded onto the gel; lane 2, extract of $B$. subtilis 168 grown in LB medium; lane 3, extract of the $h p r K$ mutant strain GP202 grown in LB medium; lane 4, extract of $E$. coli DH5 $\alpha$ grown in LB medium; lane 5, extract of $B$. subtilis 168 grown in CSE minimal medium; lane 6, extract of $B$. subtilis 168 grown in CSE minimal medium containing $1 \%(\mathrm{w} / \mathrm{v})$ glucose.
ATP/GTP-binding motif (Walker A box; Walker et al., 1982) at position 153-160 and a so-called signature sequence that is uniquely conserved in $\mathrm{HPrK} / \mathrm{P}$ proteins at position 202-211 (Galinier et al., 1998; Reizer et al., 1998 ; Fig. 2; for a recent alignment of $\mathrm{HPrK} / \mathrm{P}$ sequences see Fieulaine et al., 2001). We addressed the functional importance of these regions by site-directed mutagenesis of conserved residues. To keep major structural perturbations of the mutant proteins to a minimum, we replaced glycine residues by alanine and serine residues by threonine or alanine. The effects of the mutations on kinase and phosphatase activities are shown in Fig. 3.

A G148A substitution resulted in the abolition of both the kinase and phosphatase activities, which demonstrates that this residue is important for these activities (Fig. 3, lane 4). This residue is universally conserved among $\mathrm{HPrK} / \mathrm{P}$ proteins and may be important for structural reasons.

Several mutations in the presumptive Walker A box motif resulted in reduced enzyme activities. Both phosphatase and kinase activities were impaired by a G153A mutation (Fig. 3, lane 5). There was no phosphatase activity in the G158A variant, but this mutant protein retained some kinase activity (Fig. 3, lane 8 ). The serine residue in the Walker $\mathrm{A}$ box has been shown to be important for $\mathrm{Mg}^{2+}$ binding (Saraste et al., 1990). The activities exhibited by the enzymes with the S155T or S160T mutations were similar to those of the wild-type protein. The threonine residue might replace the serine in $\mathrm{Mg}^{2+}$ binding. An S155A replacement had also little effect on the enzyme activity. Most mutations in this region had at least a weak effect on both the kinase and phosphatase activities, with residues G153 and G158 being most important. Thus, as seen in the bifunctional E. coli isocitrate dehydrogenase kinase/phosphatase the kinase and phosphatase activities are linked to each other (Ikeda et al., 1992). This is not always the case, as evidenced by some other bifunctional kinases/phosphatases such as 6-phosphofructo-2-kinase/fructose-2,6bisphosphatase from hepatocytes or the E. coli EnvZ protein (Vertommen et al., 1996; Zhu et al., 2000).

The G207A mutation in the signature sequence gave a phenotype similar to the G158A mutation since it resulted in reduced kinase activity and loss of phosphatase activity (Fig. 3, lane 10). This region, which forms a $\beta$-strand in HPrK/P of L. casei (Fieulaine et al., 2001 ), is probably not responsible for FBP binding since the mutant protein could still be stimulated by FBP (data not shown). Thus, the importance of this region for enzyme activity may indicate that the signature sequence is involved in interaction with $\mathrm{HPr} / \mathrm{HPr}-(\operatorname{Ser} 46)-\mathrm{P}$.

In a recent study of $\mathrm{HPrK} / \mathrm{P}$ from $L$. casei, several residues important for enzyme activity were identified (Monedero et al., 2001). Interestingly, several mutations in L. casei HPrK/P also resulted in a reduction or loss of phosphatase activity whereas no mutations specifically affecting kinase activity were found. As observed in this study, a mutation of the conserved glycine residue in the Walker A box (G158 in B. subtilis, G160 in L. casei) 


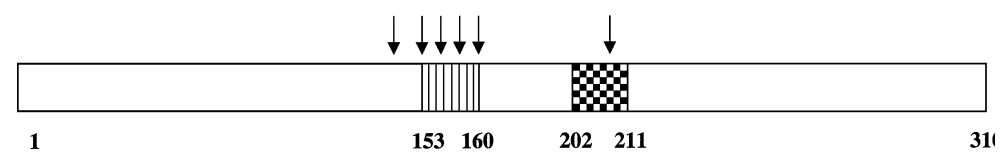

Walker A box $\quad \mathrm{GX}_{4} \mathrm{GKS}$

Fig. 2. Organization of functional regions of HPrK/P. The positions of the Walker A box nucleotide-binding motif and the signature sequence are indicated. The positions of mutations studied in this work are indicated by arrows.

(a)

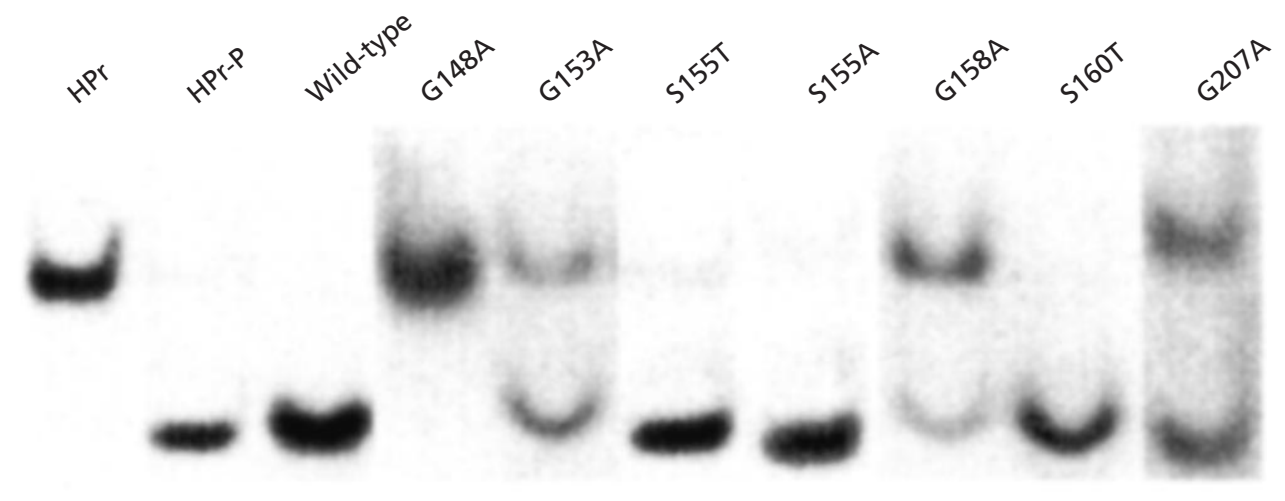

(b)

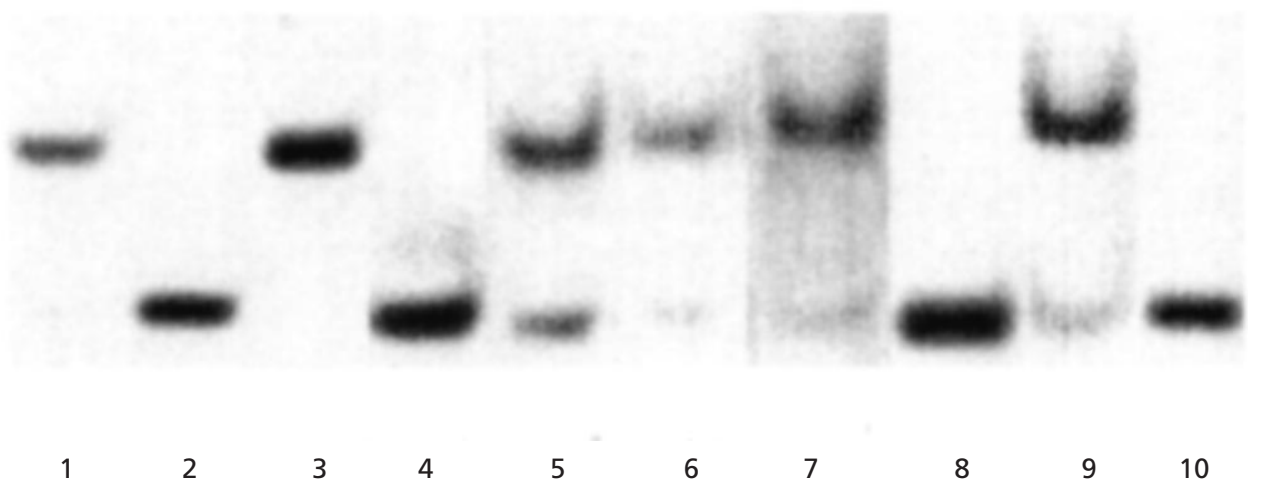

Fig. 3. Kinase (a) and phosphatase (b) activities of mutant HPrK/P proteins. For kinase activity assays, $1 \mu \mathrm{g}$ of the different mutant forms of HPrK/P proteins were incubated with $4 \mu \mathrm{g} \mathrm{HPr}$ in the assay buffer containing $10 \mathrm{mM}$ ATP and $10 \mathrm{mM}$ FBP for $15 \mathrm{~min}$ at $37^{\circ} \mathrm{C}$. For phosphatase activity assays, $1 \mu \mathrm{g}$ of the different mutant forms of HPrK/P proteins were incubated with $4 \mu \mathrm{g}$ (His) ${ }_{6}$ - $\mathrm{HPr}$-Ser-46-P in the assay buffer containing $10 \mathrm{mM} \mathrm{P}$ for $15 \mathrm{~min}$ at $37^{\circ} \mathrm{C}$.

resulted in loss of phosphatase and reduction of kinase activities. In the structure of $L$. casei $\mathrm{HPrK} / \mathrm{P}$, the glycine is located at the surface of one trimer and is in direct contact with another subunit (Fieulaine et al., 2001).

\section{In vivo consequences of hprK mutations in B. subtilis}

In previous studies with B. subtilis, the $h p r K$ gene was disrupted by insertion of a reporter gene (Galinier et al., 1998; Reizer et al., 1998). As a result, the possibility of polar effects on the expression of the downstream genes cannot be completely excluded. In order to rule out this possibility we introduced $h p r K$ alleles containing singlebase substitutions into the $B$. subtilis chromosome.
These included $h p r K$ alleles expressing $\mathrm{HPrK} / \mathrm{P}$ with neither kinase nor phosphatase activities (G148A) or only partial kinase activity (G158A or G207A) (Fig. 3). To examine the effect of different $h p r K$ alleles in $B$. subtilis, the strains were grown in CSE medium containing xylose in the presence or absence of glucose. The doubling times and $\beta$-galactosidase activities were determined (Table 3). Expression of the reporter was severely repressed (175-fold) in the presence of glucose in the wild-type strain. In contrast, $\beta$-galactosidase activity in strain GP406 ( $h p r K$ G148A) was similar when cells were grown with or without glucose. This was expected, since in the absence of any $\mathrm{HPrK} / \mathrm{P}$ activity there would be no synthesis of $\mathrm{HPr}$-(Ser46)-P and hence no repression of $x y n P$ transcription. The doubling time 
Table 3. Expression of a xynP-lacZ fusion in B. subtilis hprK mutant strains

\begin{tabular}{|c|c|c|c|c|c|}
\hline \multirow[t]{2}{*}{ Strain } & \multirow[t]{2}{*}{ Relevant $h p r K$ allele } & \multicolumn{2}{|c|}{$\begin{array}{l}\beta \text {-Galactosidase activity } \\
{\left[\text { units }(\mathrm{mg} \text { protein })^{-1}\right]^{*}}\end{array}$} & \multicolumn{2}{|c|}{ Doubling time $(\min ) \dagger$} \\
\hline & & CSE + glucose & CSE & $\mathrm{CSE}+$ glucose & CSE \\
\hline QB7144 & Wild-type & 4 & 703 & 68 & 90 \\
\hline GP406 & hprK G148A & 920 & 1335 & 68 & 92 \\
\hline GP407 & hprK G158A & 6 & 68 & 73 & 125 \\
\hline GP408 & hprK G207A & 3 & 107 & 76 & 115 \\
\hline
\end{tabular}

*Cells were grown in CSE medium with or without glucose $(0.5 \%)$ and xylose as inducer. At $\mathrm{OD}_{600}$ $0 \cdot 6-0 \cdot 8$, the cells were harvested and lysed with lysozyme and DNase. The supernatant obtained after centrifugation was used for estimation of $\beta$-galactosidase activity.

† Cell growth was monitored in CSE medium with or without glucose $(0 \cdot 5 \%)$ as $\mathrm{OD}_{600}$ until the cultures entered stationary phase. Doubling time was estimated from a semi-logarithmic plot of time vs $\mathrm{OD}_{600}$.

of this mutant strain was similar to that of the wild-type. This mutant thus behaved similarly to a $h p r K$ null mutant, for which it was shown that the lack of carbon catabolite repression was not due to a defect in PTSmediated uptake of the sugars (Reizer et al., 1998). Strains GP407 ( $h p r K$ G158A) and GP408 ( $h p r K$ G207A) grown in the absence of glucose exhibited reduced $\beta$ galactosidase activity compared to the wild-type. This reduced expression of the $x y n P-l a c Z$ fusion was further repressed by glucose, suggesting that CCR was functional in these mutants. The reduced expression in the absence of glucose could be due to permanent repression exerted by HPr-(Ser46)-P and CcpA since the mutant $\mathrm{HPrK} / \mathrm{P}$ proteins lack phosphatase activity. Similar results have recently been obtained with mutant $L$. casei $h p r K$ alleles resulting in reduction of phosphatase activity (Monedero et al., 2001). Moreover partial loss of kinase activity and non-dephosphorylation of HPr(Ser46)-P probably resulted in impaired growth as reflected in the increased doubling time in both the presence and absence of glucose. These results demonstrate that disruption of one of the activities of the bifunctional $\mathrm{HPrK} / \mathrm{P}$ is more deleterious for growth than is disruption of both activities. Thus, from a physiological point of view, it would be advantageous to have two opposing activities interlinked on a single polypeptide since the probability of disruption of both activities by mutations is higher. Under such circumstances, the growth probably remains unaffected, as seen in the case of the $B$. subtilis strain expressing $\mathrm{HPrK} / \mathrm{P}$ deficient in both activities.

\section{ACKNOWLEDGEMENTS}

Michael Müller is acknowledged for help with some experiments. This work was supported by a grant to J.S. and W.H. from the Deutsche Forschungsgemeinschaft and the Fonds der Chemischen Industrie. K.G.H. is grateful to the Alexander von Humboldt Stiftung for the award of a fellowship.

\section{REFERENCES}

Bachem, S., Faires, N. \& Stülke, J. (1997). Characterization of the presumptive phosphorylation sites of the Bacillus subtilis glucose permease by site-directed mutagenesis: implication in glucose transport and catabolite repression. FEMS Microbiol Lett 156, 233-238.

Brochu, D. \& Vadeboncoeur, C. (1999). The HPr(Ser) kinase of Streptococcus salivarius: purification, properties, and cloning of the hprK gene. J Bacteriol 181, 709-717.

Deutscher, J. \& Engelmann, R. (1984). Purification and characterization of an ATP-dependent protein kinase from Streptococcus faecalis. FEMS Microbiol Lett 23, 157-162.

Deutscher, J. \& Saier, M. H., Jr (1983). ATP-dependent protein kinase-catalyzed phosphorylation of a seryl residue in $\mathrm{HPr}$, a phosphate carrier protein of the phosphotransferase system in Streptococcus pyogenes. Proc Natl Acad Sci U S A 80, 6790-6794.

Deutscher, J., Küster, E., Bergstedt, U., Charrier, V. \& Hillen, W. (1995). Protein kinase-dependent $\mathrm{HPr} / \mathrm{CcpA}$ interaction links glycolytic activity to carbon catabolite repression in Grampositive bacteria. Mol Microbiol 15, 1049-1053.

Dossonnet, V., Monedero, V., Zagorec, M., Galinier, A., PerezMartinez, G. \& Deutscher, J. (2000). Phosphorylation of HPr by the bifunctional HPr kinase/P-Ser-HPr phosphatase from Lactobacillus casei controls catabolite repression and inducer exclusion but not inducer expulsion. J Bacteriol 182, 2582-2590.

Faires, N., Tobisch, S., Bachem, S., Martin-Verstraete, I., Hecker, M. \& Stülke, J. (1999). The catabolite control protein CcpA controls ammonium assimilation in Bacillus subtilis. $J \mathrm{Mol}$ Microbiol Biotechnol 1, 141-148.

Fieulaine, S., Morera, S., Poncet, S., Monedero, V., GueguenChaignon, V., Galinier, A., Janin, J., Deutscher, J. \& Nessler, S. (2001). X-ray structure of HPr kinase: a bacterial protein kinase with a P-loop nucleotide-binding domain. EMBO J 20, 39173927.

Galinier, A., Haiech, J., Kilhoffer, M.-C., Jaquinod, M., Stülke, J., Deutscher, J. \& Martin-Verstraete, I. (1997). The Bacillus subtilis crh gene encodes a HPr-like protein involved in carbon catabolite repression. Proc Natl Acad Sci U S A 94, 8439-8444.

Galinier, A., Kravanja, M., Engelmann, R., Hengstenberg, W., Kilhoffer, M.-C., Deutscher, J. \& Haiech, J. (1998). New protein 
kinase and protein phosphatase families mediate signal transduction in bacterial catabolite repression. Proc Natl Acad Sci U S A 95, 1823-1828.

Galinier, A., Deutscher, J. \& Martin-Verstraete, I. (1999). Phosphorylation of either Crh or HPr mediates binding of CcpA to the Bacillus subtilis xyn cre and catabolite repression of the $x y n$ operon. J Mol Biol 286, 307-314.

Himmelreich, R., Hilbert, H., Plagens, H., Pirkl, E., Li, B.-C. \& Herrmann, R. (1996). Complete sequence analysis of the genome of the bacterium Mycoplasma pneumoniae. Nucleic Acids Res 24, 4420-4449.

Huynh, P. L., Jankovic, I., Schnell, N. F. \& Brückner, R. (2000). Characterization of an HPr kinase mutant of Staphylococcus xylosus. J Bacteriol 182, 1895-1902.

Ikeda, T. P., Houtz, E. \& LaPorte, D. C. (1992). Isocitrate dehydrogenase kinase/phosphatase: identification of mutations which selectively inhibit phosphatase activity. J Bacteriol 174, 1414-1416.

Jault, J. M., Fieulaine, S., Nessler, S., Gonzalo, P., Di Pietro, A., Deutscher, J. \& Galinier, A. (2000). The HPr kinase from Bacillus subtilis is a homo-oligomeric enzyme which exhibits strong positive cooperativity for nucleotide and fructose 1,6-bisphosphate binding. J Biol Chem 275, 1773-1780.

Jones, B. E., Dossonnet, V., Küster, E., Hillen, W., Deutscher, J. \& Klevit, R. E. (1997). Binding of the catabolite repressor protein CcpA to its DNA target is regulated by phosphorylation of its corepressor HPr. J Biol Chem 272, 26530-26535.

Kravanja, M., Engelmann, R., Dossonnet, V. \& 7 other authors (1999). The hprK gene of Enterococcus faecalis encodes a novel bifunctional enzyme: the HPr kinase/phosphatase. Mol Microbiol 31, 59-66.

Kunst, F. \& Rapoport, G. (1995). Salt stress is an environmental signal affecting degradative enzyme synthesis in Bacillus subtilis. J. Bacteriol 177, 2403-2407.

Lindner, C., Stülke, J. \& Hecker, M. (1994). Regulation of xylanolytic enzymes in Bacillus subtilis. Microbiology $\mathbf{1 4 0}$, 753-757.

Martin-Verstraete, I., Deutscher, J. \& Galinier, A. (1999). Phosphorylation of HPr and Crh by HprK, early steps in the catabolite repression signalling pathway for the Bacillus subtilis levanase operon. J Bacteriol 181, 2966-2969.

Miller, J. (1972). Experiments in Molecular Genetics. Cold Spring Harbor NY: Cold Spring Harbor Laboratory.
Monedero, V., Poncet, S., Mijakovic, I., Fieulaine, S., Dossonnet, V., Martin-Verstraete, I., Nessler, S. \& Deutscher, J. (2001). Mutations lowering the phosphatase activity of HPr kinase/ phosphatase switch off carbon metabolism. EMBO J 20, 39283937.

Reizer, J., Hoischen, C., Titgemeyer, F., Rivolta, C., Rabus, R., Stülke, J., Karamata, D., Saier, M. H., Jr \& Hillen, W. (1998). A novel protein kinase that controls carbon catabolite repression in bacteria. Mol Microbiol 27, 1157-1169.

Reizer, J., Bachem, S., Reizer, A., Arnaud, M., Saier, M. H., Jr \& Stülke, J. (1999). Novel phosphotransferase system genes revealed by genome analysis - the complete complement of PTS components encoded within the genome of Bacillus subtilis. Microbiology 145, 3419-3429.

Sambrook, J., Fritsch, E. F. \& Maniatis, T. (1989). Molecular Cloning: a Laboratory Manual, 2nd edn. Cold Spring Harbor, NY : Cold Spring Harbor Laboratory.

Saraste, M., Sibbald, P. R. \& Wittinghofer, A. (1990). The P-loop - a common motif in ATP- and GTP-binding proteins. Trends Biochem Sci 15, 430-434.

Schirmer, F., Ehrt, S. \& Hillen, W. (1997). Expression, inducer spectrum, domain structure, and function of MopR, the regulator of phenol degradation in Acinetobacter calcoaceticus NCIB8250. $J$ Bacteriol 179, 1329-1336.

Stülke, J. \& Hillen, W. (2000). Regulation of carbon catabolism in Bacillus species. Annu Rev Microbiol 54, 849-880.

Stülke, J., Martin-Verstraete, I., Zagorec, M., Rose, M., Klier, A. \& Rapoport, G. (1997). Induction of the Bacillus subtilis ptsGHI operon by glucose is controlled by a novel antiterminator, GlcT. Mol Microbiol 25, 65-78.

Vertommen, D., Bertrand, L., Sontag, B., Di Pietro, A., Louckx, M. P. , Vidal, H., Hue, L. \& Rider, M. H. (1996). The ATP-binding site in the 2-kinase domain of liver 6-phosphofructo-2-kinase/ fructose-2,6-bisphosphatase. J Biol Chem 271, 17875-17880.

Walker, J. E., Saraste, M., Runswick, M. J. \& Gay, N. J. (1982). Distantly related sequences in the alpha- and beta-subunits of ATP synthase, myosin, kinases and other ATP-requiring enzymes and a common nucleotide binding fold. EMBO J 1, 945-951.

Zhu, Y., Qin, L., Yoshida, T. \& Inouye, M. (2000). Phosphatase activity of histidine kinase EnvZ without kinase catalytic domain. Proc Natl Acad Sci US A 97, 7808-7813.

Received 10 January 2002; revised 22 February 2002; accepted 25 February 2002. 